\title{
TIME BEFORE SURGERY VS RECOVERY OF LUMBAR HERNIATION. CHILEAN REALITY IN THE PUBLIC HEALTH SYSTEM
}

\author{
TEMPO PRÉVIO CIRURGIA VIS RECUPERAÇÃO EM HÉRNIA LOMBAR. A REALIDADE \\ CHILENA NA ATENÇÃO PÚBLICA
}

\section{TIEMPO ANTES DE LA CIRUGIA VERSUS RECUPERACIÓN DE HERNIA LUMBAR. REALIDAD CHILENA EN ATENCION PÜBLICA}

\author{
Marcos Egor Ganga Villagrán, ${ }^{1}$ Juan Pablo Santelices lopez, ${ }^{2}$ Patricio Omar Almonacid Lorca, ${ }^{3}$ Loreto Consuelo Pulido Quintana, ${ }^{4}$ \\ Andrea Cecilia Palacios Castillo ${ }^{2}$ \\ 1. Universidad de Chile, Facultad de Medicina, Complejo Hospitalario San José, Traumatology Department, Spine Group, Santiago, Chile. \\ 2. Complejo Hospitalario San José, Orthopedics and Traumatology Service, Spine Group, Santiago, Chile. \\ 3. Universidad de Chile, Facultad de Medicina, Traumatology Department, Santiago, Chile. \\ 4. Universidad Austral de Chile, Facultad de Medicina, Valdivia, Chile.
}

\begin{abstract}
Objective: To evaluate the influence between the time elapsed since the onset of symptoms and the surgery of lumbar HNP in the final functional recovery of the comprehensive treatment of patients. Methods: Retrospective descriptive study of cases of HNP treated by lumbar discectomy between 2009 and 2015 by the spine team of the Hospital San José, using SPSS (version 22 of IBM) for the statistical analysis. Results: Of 110 patients subject to surgery, 54 were recruited (22 women and 32 men), between 18 and 75 years old, with an average age of 43 years. Eighty percent of patients are active workers, $76 \%$ without comorbidities. The predominant level affected was L4/L5 with $52 \%$ of the cases. The mean progression time of the symptoms before the first consultation was 27 months, the waiting time between the consultation and the surgery was 5.6 months. Conclusions: Eighty-six percent of the patients -presented good results in VAS. The Oswestry questionnaire reached a positive result in 90\%, a minimum disability in 40\%, moderate in $50 \%$ and maximum in $10 \%$. No statistical relationship was achieved between any of the evaluated variables and the outcome of the surgery. Level of Evidence IV; Therapeutic Study - Investigation of Treatment Results.
\end{abstract}

Keywords: Diskectomy; Quality of Life; Outcomes Assessment; Public Health.

\section{RESUMO}

Objetivo: Avaliar a influência entre o tempo de início dos sintomas e a resolução cirúrgica da hérnia lombar na recuperação funcional no tratamento dos pacientes. Métodos: Estudo descritivo retrospectivo de casos de hérnia lombar com discectomia entre 2009 e 2015 no "Hospital San José", usando análise estatística SPSS (versão 22 da IBM). Resultados: De 110 pacientes operados, se recrutaram 54 pacientes para o estudo, dos quais 22 são mulheres e 32 homens, entre 18 e 75 anos com uma média de idade de 43 anos. $80 \%$ dos pacientes são trabalhadores ativos, 76\% não apresentam co-morbidades. O nível mais frequentemente afetado foi L4/L5 com 52\% dos casos. O tempo médio de evolução da sintomatologia antes da primeira consulta foi de 27 meses, o tempo de espera entre consulta e resolução cirúrgica, foi de cinco, seis meses. Conclusões: $86 \%$ dos pacientes mostraram bons resultados em EVA. Segundo o questionário OSWESTRY, se obtiveram bons resultados num 90\% dos casos; uma deficiência mínima em um 40\%; moderada em 50\% e máxima em $10 \%$ dos pacientes. Se observou ainda falta de relacão estadística entre as variáveis avaliadas e o resultado da cirugía. Nível de Evidência IV; Os Resultados do Tratamento de Estudo Terapêutico - Pesquisa.

Descritores: Discotomia; Qualidade de Vida; Avaliação de Resultados; Saúde Pública.

\section{RESUMEN}

Objetivos: Evaluar la influencia entre el tiempo transcurrido desde el inicio de los síntomas y la resolución quirúrgica de la HNP lumbar en la recuperación funcional final en el tratamiento integral de pacientes. Métodos: Estudio descriptivo retrospectivo de casos operados de HNP con discectomía lumbar entre 2009 y 2015 por el equipo de columna del Hospital San José, utilizando SPSS (versión 22 de IBM) para el análisis estadístico. Resultados: De 110 pacientes operados, se reclutaron 54, 22 mujeres y 32 hombres, entre los 18 y 75 años, promedio de edad de 43 años. Ochenta por ciento de los pacientes son laboralmente activos, un $76 \%$ no presentan comorbilidades. El nivel predominante afectado fue L4/L5 con 52\% de los casos. El tiempo de evolución promedio de la sintomatología antes de la primera consulta fue 27 meses, el tiempo de espera entre la consulta y la resolución quirúrgica, fue 5,6 meses. Conclusiones: Ochenta y seis por ciento de los pacientes presentaron resultados positivos en EVA. El cuestionario Oswestry obtuvo un resultado positivo en 90\%, discapacidad mínima en 40\%, moderada en 50\% y máxima en 10\%. No se logró establecer relación estadística entre ninguna de las variables evaluadas y el resultado final de la cirugía. Nivel de Evidencia IV; Estudio terapéutico - Investigación de los resultados de tratamiento.

Descriptores: Discectomía; Calidad de Vida; Evaluación de Resultado; Salud Pública. 


\section{INTRODUCTION}

Sciatalgia due to herniation of the nucleus pulposus of the intervertebral disc is one of the most common symptoms of spinal disease. The lifetime and annual incidence range from 13 to 40\% and 1 to $5 \%$, respectively, ${ }^{1,2}$ with herniation of the nucleus pulposus being the most common indication for spine surgery. ${ }^{3}$

The natural course is usually favorable. ${ }^{4}$ According to Anderson et al., ${ }^{5}$ surgery is recommended for severe, constant, incapacitating pain that does not respond to conservative treatment and for severe and progressive neurological deficit. 6,7

Since the first lumbar discectomy in $1933,{ }^{8}$ it has become a widely accepted intervention for radiculopathy resulting from acute herniation of the lumbar intervertebral disc.8,9 Even though today there are new techniques, the main principle of the procedure remains unchanged with respect to that proposed by Mixter and Barr: ${ }^{8}$ elimination of the compressive and irritating disc material in the vicinity of the affected nerve root. ${ }^{10}$

The advantages of surgical intervention and its efficacy as compared to non-surgical intervention have been highlighted in various publications. 9,11 However, to date there is no conclusive information as to whether the moment of surgery and the duration of symptoms prior to the surgery have a prejudicial impact on the postoperative results. ${ }^{10,12,13}$

The studies by Hurme et al. ${ }^{14}$ and Nygaard et al. ${ }^{15}$ maintain that an increase in the duration of the symptoms decreases the success of the outcome following lumbar discectomy. However, more recently, Suzuki et al., ${ }^{16}$ did not observe any association between the moment of the surgical intervention and the postoperative outcome. In their 2014 systematic review, Schoenfeld et al. concluded that the duration of symptoms quite probably has an adverse effect on pain and functional recovery following lumbar discectomy, with a possible cutoff at 6 months following the onset of symptoms. ${ }^{17}$

At the same time, Sabnis et al. added that the time with symptomatology alone should not be the basis for a recommendation of surgery, given that there are other variables that negatively affect the outcome, such as social factors (long-standing medical leave, low educational level, single or divorced status), biological (more than 40 years of age) factors, etc. ${ }^{18}$

Due to the inconsistent results in the available literature regarding a correlation between duration of symptoms and clinical outcome and to the absence of national studies of this type, we decided to evaluate patients who underwent lumbar discectomy at the Complejo Hospitalario San José (CHSJ). Our hypothesis is that there is a relationship between the time waiting for surgical resolution and the outcome of surgeries for herniation of the nucleus pulposus.

\section{METHODS}

This retrospective descriptive study was conducted at CHSJ, a public hospital located in the Northern area of the Metropolitan Region of Santiago, Chile.

Prior to launching the study, approval was obtained from the Institutional Review Board of the Servicio de Salud Metropolitano Norte (CARTA AE No 045/2016). In the study, we considered ethical aspects such as the safekeeping of patient identity, the informed consent of each patient, and all the information obtained for purposes related to this research, in compliance with Law 20.584 and the bioethics norms in force. Each patient was assigned a code to safeguard confidentiality and these codes were eliminated at the end of the investigation.

Probability convenience sampling was used to build our sample. The total universe of cases evaluated corresponded to men and women older than 15 years of age who were operated by the CHSJ Spine team for lumbar discectomy for HNP between 2009 and 2015. Patients with immediate surgical complications were excluded, yielding a total of 110 patients in the sample.

The data was collected in telephone interviews.

Using clinical records and surgical protocols, we identified variables such as sex, age, comorbidities, work activity, tobacco use, neurological deficit, and laterality, preoperative treatment received (epidural steroid injection and/or kinesiotherapy), the time transpired from the onset of symptoms to the first consultation in our center, and the time transpired until the final surgical resolution. The level of the herniation of the nucleus pulposus was defined by magnetic resonance of the lumbar spine.

The interviews were conducted in June and July of 2016.

\section{Measurement tools}

The Oswestry low back pain disability questionnaire ${ }^{19}$ (Attachment 1) and the visual analog scale (VAS) ${ }^{20}$ were applied.

We used descriptive statistical tools. The resulting data were tabulated and analyzed using SPSS software (version 22, IBM).

\section{RESULTS}

From the universe of 110 patients who underwent surgery during the study period, 54 (59.4\%) were recruited for the study; 22 women and 32 men, or $41 \%$ and $59 \%$, respectively, with an average age of 43 years for both sexes (ranging from 18 to 75 years of age). Figure 1

\section{Cases, Age in years, Percentage}

Eighty percent (80\%) of the patients were employed, $41 \%$ of whom had completed between 1 and 6 months of medical leave.

Regarding comorbidities encountered among the patients evaluated, $76 \%$ (41 cases) were healthy and of the remaining $24 \%, 16 \%$ (9 cases) presented high blood pressure as the only medical issue and $12 \%$ presented diabetes mellitus with or without insulin dependence and associated or not with high blood pressure. A total of $56 \%$ of the patients were active smokers

In terms of the clinical data about the nucleus pulposus herniation, laterality had equal predominance, 50\% right and 50\% left. Forty percent $(40 \%)$ of the patients had sensory and motor deficit, $34 \%$ with sensory deficit only, and $26 \%$ with motor deficit only. The predominant level (52\% of cases) was between L4/L5, followed by L5/S1(40\% of cases). Figure 2

\section{Level, Percentage}

Only 21\% (39 cases) of the patients were given corticosteroid infiltration prior to the surgery, while 54\% (29 cases) received no type of kinetic therapy prior to surgery.

The average evolution time of the symptoms prior to the first consultation was 27 months (between 2.5 and 613 months) and the average wait time between the consultation and final surgical resolution was 5.6 months ( $0.5-24$ months).

Applying the VAS at the time of admission, 73\% (39 cases) reported that this was the worst pain experienced in their lifetime (VAS 10), with an exit score of 3 in 26\% (14 cases). The VAS results were divided into three groups, in which a score of 1 to 4 was considered a good outcome, 5 to 7 a fair outcome, and from 8 to 10 a poor outcome. Eighty-six percent (86\%) of the respondents presented positive outcomes in the review (56\% good, 30\% fair, and 14\% poor results).

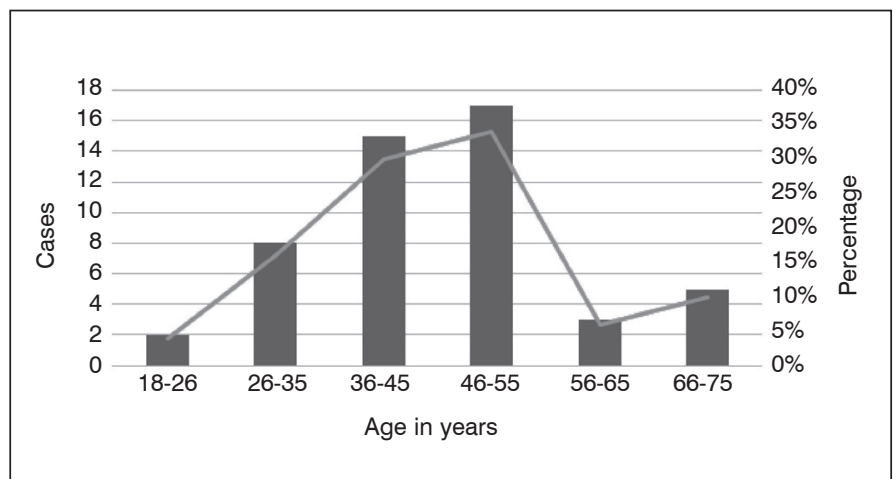

Figure 1. Distribution by age of patients operated on for lumbar discectomy for herniation of the nucleus pulposus between 2009 and 2015 by the Spine team of the Complejo Hospitalario San José, Región Metropolitana, Santiago, Chile. 
When we applied the Oswestry low back pain disability questionnaire and grouped the results the same way, we obtained positive results in $90 \%$ of cases reviewed, with minimum disability in $40 \%$, moderate in $50 \%$, and maximum disability in $10 \%$.

To assess the relationship between the previously described variables and the lumbar discectomy results, a series of linear regression analyses was performed in which each of the variables evaluated was treated as an independent variable and the surgical outcome was treated as a dependent variable.

By grouping the data and correlating them statistically, we were not able to establish a statistical association between any of the selected variables and the postoperative results. Table 1

The partial regression test correlating the surgical result and wait time obtained a dispersion for which no correlation could be confirmed. Similarly, when the ANOVA test with F-statistic was applied, the critical values were lower than expected (0.52).

When trying to calculate a correlation coefficient with the Spearman test, a Rho equal to $0.06(p=0.65)$ was obtained, resulting in the rejection of the original hypothesis. Figure 3

\section{DISCUSSION}

From the analysis of results obtained from the patients who underwent lumbar discectomy at the Complejo Hospitalario San José (CHSJ), it can be stated that the population served in Figures 1 and 2 is essentially identical to that described by international statistics, ${ }^{21}$ which allows adequate which means that the population surveyed is a suitable representation and, therefore, validates the data collection method.

The average patient wait times prior to lumbar discectomy were less than 6 months during the last 6 years, complying fully with

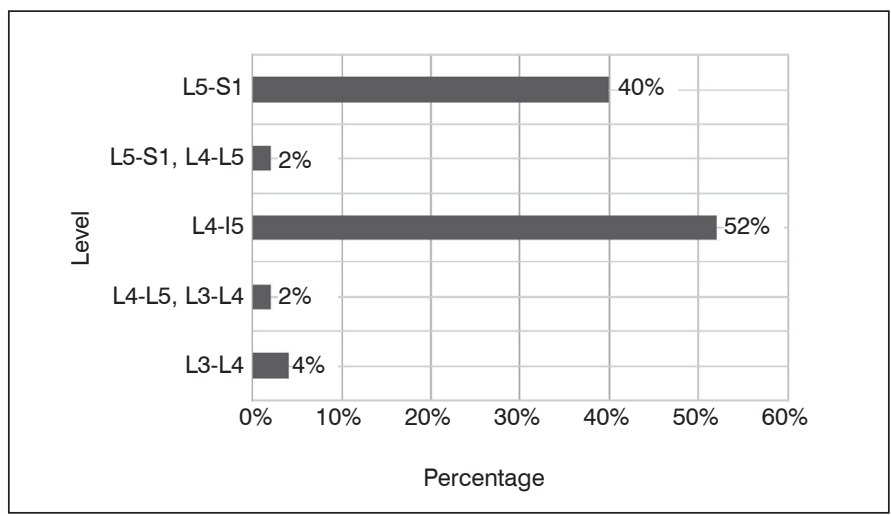

Figure 2. Percentage of distribution by level of nucleus pulposus herniation in patients who underwent discectomy between 2009 and 2015 performed by the Spine team of the Complejo Hospitalario San José, Región Metropolitana, Santiago, Chile. the ministerial requirements given in the National Health Ministry (MINSAL) clinical guidelines. ${ }^{22}$

When we administered the VAS to the patients, the score improved from an average of 9 at the first control point to a score of 3 at the end (late postoperative control), reflecting satisfactory final outcomes in $90 \%$ of the cases at CHSJ.

In their 2014 systematic review, Schoenfeld et. al. pointed out that the duration of symptoms probably has an adverse effect on functional recovery following lumbar discectomy. However, in our study there was no evidence of a temporal correlation between wait times and the final surgical outcome in terms of patient satisfaction, not ruling out the influence that social and biological variables could have on the final results. ${ }^{18}$ The foregoing shows that the timeframes described in the international literature ${ }^{16}$ and in the MINSAL guidelines ${ }^{22}$ are arbitrary and lacking in evidence-based medical fundamentals and are more related to periods of medical leave in the working population. The above is based on the direct correlation in $75 \%$ of the cases.

The results from both the VAS and OSWESTRY scales were similar and statistically significant $(S D=1,518)$ (Figure 4), which would be interpreted as the capacity to represent disability related to the pathology, which is directly proportional to personally perceived pain.

The low number of useful cases for a review of the responses from patients who underwent lumbar discectomy for herniation of the nucleus pulposus is mainly due to the inadequacy of telephone records and patient follow-up in the SOME system in our hospital center and it is a weakness to be improved in the future.

The final satisfactory surgical results in our center are close to $90 \%$, demonstrating the great resolution capacity for this pathology in a high-complexity public center.

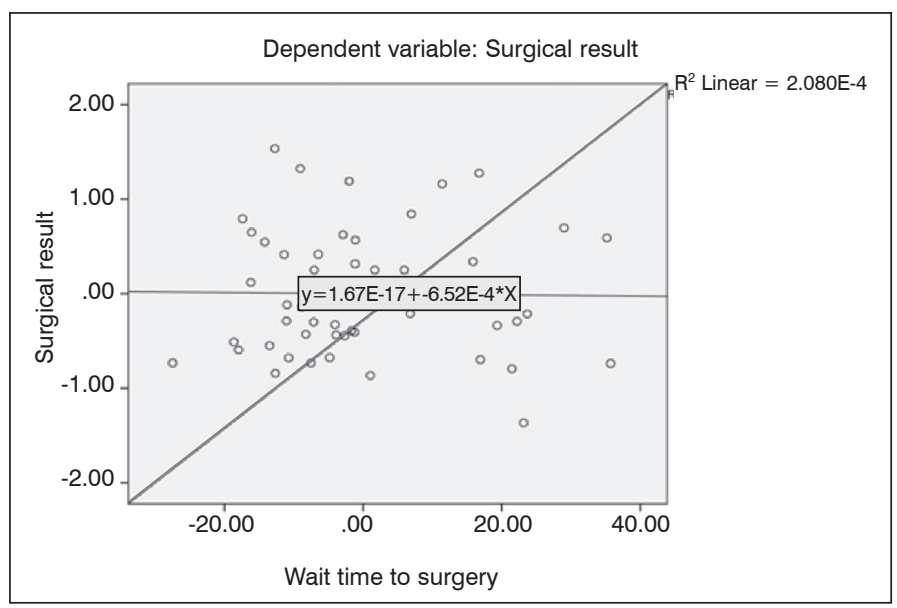

Figure 3. Graph of partial regression.

Table 1. Results of the linear regression analysis.

\begin{tabular}{|c|c|c|c|c|c|c|c|}
\hline \multicolumn{8}{|c|}{ Coefficients $^{a}$} \\
\hline \multirow{2}{*}{ Model } & \multicolumn{2}{|c|}{ Non-standardized coefficients } & \multirow{2}{*}{$\begin{array}{c}\begin{array}{c}\text { Standardized } \\
\text { coefficients }\end{array} \\
\text { Beta }\end{array}$} & \multirow{2}{*}{$t$} & \multirow{2}{*}{ Sig. } & \multicolumn{2}{|c|}{$95.0 \%$ confidence interval for $B$} \\
\hline & B & Standard error & & & & Lower limit & Upper limit \\
\hline Wait time to surgery & -.001 & .007 & -.015 & -.092 & .927 & -.015 & .014 \\
\hline Complications & .616 & .313 & .296 & 1.971 & .056 & -.015 & 1.248 \\
\hline Infiltration & -.261 & .276 & -.145 & -.949 & .348 & -.818 & .295 \\
\hline Age & -.006 & .009 & -.106 & -.659 & .514 & -.024 & .012 \\
\hline Comorbidity & -.106 & .279 & -.062 & -.378 & .707 & -.670 & .459 \\
\hline Activity & .161 & .135 & .181 & 1.192 & .240 & -.111 & .433 \\
\hline
\end{tabular}

Dependent variable: surgical outcome. 


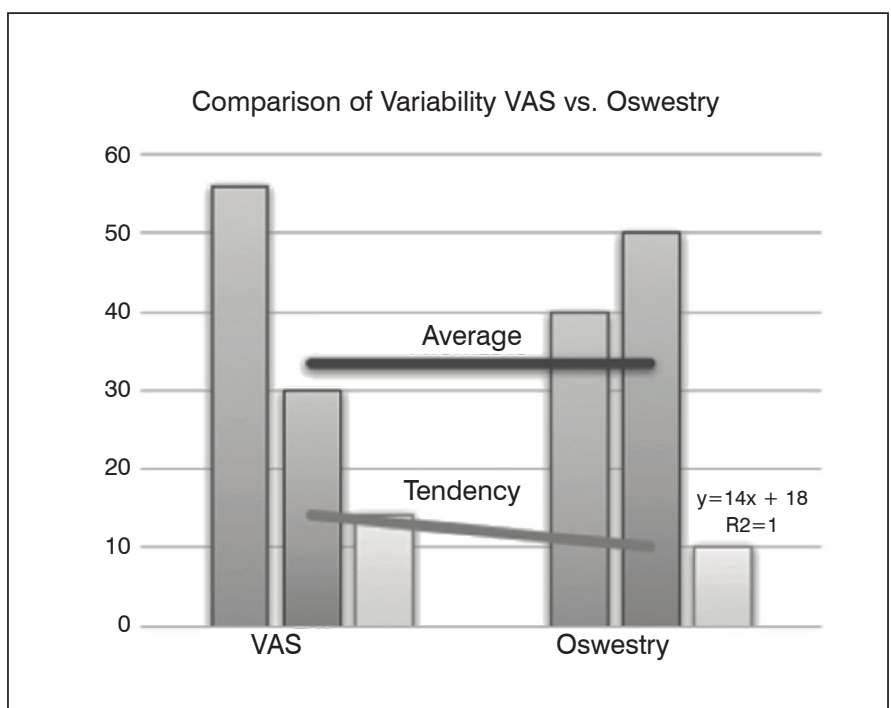

Figure 4. Comparative graph - Average vs. Tendency between VAS and OSWESTRY.

\section{CONCLUSION}

The epidemiology presented in this evaluation agrees with that presented in the published international literature.

However, from the results obtained it is not possible to define a maximum wait time for surgical resolution.

Patient registration and follow-up in the long term must be improved, given that outdated information makes long-term follow-up, the correct identification of late complications, and evaluation of the results in terms of the learning curve of the surgical team impossible.

The surgical experience demonstrated in our healthcare center is based on the combined experience of the group of Hospital San José surgeons and we were not able to identify whether the final results were related to the surgery itself or counted on the reinforcement of the other clinical units of the same healthcare center.

We propose that a prospective registry with pre- and postoperative VAS and Oswestry results be established in the future.

All authors declare no potential conflict of interest related to this article.

CONTRIBUTION OF THE AUTHORS: Each author made significant individual contributions to this manuscript. JPSL (0000-0002-4858-1671)*, POAL $(0000-0002-0363-3773)^{\star}$, LCPQ (0000-0002-3600-1887)*, and ACPC (0000-0002-8581-7348* participated actively in the discussion of the results. MEGV (0000-0002-8663-8878)*, JPSL, POAL, LCPQ, and ACPC reviewed and approved the final version of the work. *ORCID (Open Researcher and Contributor ID).

\section{REFERENCES}

1. Frymoyer JW. Back pain and sciatica. N Engl J Med. 1988:318(5):291-300.

2. Frymoyer JW. Lumbar disk disease: Epidemiology. Instr Course Lect. 1992; 41: 217-223.

3. Cherkin DC, Deyo RA, Loeser JD, Bush T, Waddell G. An international comparison of back surgery rates. Spine (Phila Pa 1976).1994; 19(11):1201-6.

4. Saal JA, Saal JS. Nonoperative treatment of herniated lumbar intervertebral disc with radiculopathy. An outcome study. Spine (Phila Pa 1976). 1989;14(4):431-7.

5. Andersson GB, Brown MD, Dvorak J, Herzoq RJ, Kambin P, Malter A, et al. Consensus summary on the diagnosis and treatment of lumbar disc herniation. Spine (Phila Pa 1976). 1996;21(suppl):75S-8S.

6. Ministerio de Salud. Guía Clínica "Hernia de Núcleo Pulposo Lumbar". Santiago: Minsal; 2013-2014.

7. Weinstein JN, Tosteson TD, Lurie JD, Tosteson AN, Hanscom B, Skinner JS, et al. Surgical vs nonoperative treatment for lumbar disk herniation: the Spine Patient Outcomes Research Trial (SPORT): a randomized trial. JAMA. 2006;296(20): 2441-50.

8. Mixter WJ, Barr JS. Rupture of the intervertebral disc with involvement of the spinal canal N Engl J Med. 1934; 211:210-5

9. Schoenfeld AJ, Weiner BK. Treatment of lumbar disc herniation: evidence-based practice. Int J Gen Med. 2010:3:209-14.

10. Atlas SJ, Keller RB, Wu YA, Deyo RA, Singer DE. Long-term outcomes of surgical and nonsurgical management of sciatica secondary to a lumbar disc herniation: 10 year results from the Maine lumbar spine study. Spine (Phila Pa 1976). 2005;30(8):927-35

11. Weinstein JN, Lurie JD, Tosteson TD, Tosteson AN, Blood EA, Abdu WA, et al. Surgical versus nonoperative treatment for lumbar disc herniation: four-year results for the Spine
Patient Outcomes Research Trial (SPORT). Spine (Phila Pa 1976). 2008:33(25):2789-800

12. Akagi $R$, Aoki $Y$, Ikeda $Y$, Nakajima F, Ohtori $S$, Takashi $K$, et al. Comparison of early and late surgical intervention for lumbar disc herniation: is earlier better? J Orthop Sci. 2010:15(3):294-8.

13. Ng LCL, Sell P. Predictive value of the duration of sciatica for lumbar discectomy: a prospective cohort study. J Bone Joint Surg Br. 2004;86(4):546-9.

14. Hurme M, Alaranta $\mathrm{H}$. Factors predicting the result of surgery for lumbar intervertebral disc herniation. Spine (Phila Pa 1976). 1987:12(9):933-8.

15. Nygaard OP, Romner B, Trumpy JH. Duration of symptoms as a predictor of outcome after lumbar disc surgery. Acta Neurochir (Wien). 1994;128(1-4):53-6.

16. Suzuki A, Matsumura A, Konishi S, Terai H, Tsujio T, Dozono S, et al. Risk factor analysis for motor deficit and delayed recovery associated with $L 4 / 5$ lumbar disc herniation. J Spinal Disord Tech. 2011:24(1):1-5

17. Schoenfeld A, Bono C. Does Surgical Timing Influence Functional Recovery After Lumbar Discectomy? A Systematic Review. Clin Orthop Relat Res. 2015;473(6):1963-70.

18. Sabnis A, Diwan A. The timing of surgery in lumbar disc prolapse: A systematic review (3). Indian J Orthop. 2014;48(2):127-35.1.

19. Flórez MT, García MA, García F, Armenteros J, Álvarez A, Martínez MD. Adaptación transcultural a la población española de la escala de incapacidad por dolor lumbar de Oswestry. Rehabilitación (Madr). 1995;29:138-45.

20. D Price, F Bush, S Long. A comparison of pain measurement characteristics of mechanical visual analogue and simple numerical rating scales. Pain. 1994;56(2):217-26.

21. Bridwell K, DeWald R. The textbook of Spinal Surgery. En: 3th ed. Lippincott Williams \& Wilkins; 2011. 


\section{Please read carefully}

These questions have been designed so that your doctor can understand to what extent your back pain affects your daily life. Answer all the questions, selecting the one response that most closely describes your case. Even if you think that more than one answer applies to your situation, mark only that which BEST describes your problem.

\section{Section 1 - Pain intensity}

$\square \quad$ I have no pain at the moment

$\square \quad$ The pain is very mild at the moment

$\square$ The pain is moderate at the moment

$\square \quad$ The pain is fairly severe at the moment

$\square \quad$ The pain is very severe at the moment

$\square$ The pain is the worst imaginable at the moment

Section 2 - Personal care (washing, dressiı

$\square$ I can look after myself normally without causing extra pain

$\square \quad$ I can look after myself normally but it causes extra pain

$\square$ It is painful to look after myself and I am slow and careful

$\square \quad$ I need some help but manage most of my personal care

$\square \quad$ I need help every day in most aspects of self-care

$\square$ I do not get dressed, I wash with difficulty and stay in bed

\section{Section 3 - Lifting}

$\square$ I can lift heavy weights without extra pain

$\square$ I can lift heavy weights but it gives extra $p$

$\square \quad$ Pain prevents me from lifting heavy weigh the floor, but I can manage if they are conveniently placed eg. on a table

$\square \quad$ Pain prevents me from lifting heavy weigh but I can manage light to medium weights they are conveniently positioned

$\square \quad$ I can lift very light weights

I cannot lift or carry anything at all

\section{Section 4 - Walking*}

Pain does not prevent me walking any dis

$\square$ Pain prevents me from walking more than 1 mile

$\square \quad$ Pain prevents me from walking more than $1 / 2$ mile

$\square$ Pain prevents me from walking more than 100 yards

$\square \quad$ I can only walk using a stick or crutches

$\square \quad$ l am in bed most of the time
Section 5 - Sitting

I can sit in any chair as long as I like

I can only sit in my favourite chair as long as I like

Pain prevents me sitting more than one hour

Pain prevents me from sitting more than 30 minutes

$\square$ Pain prevents me from sitting more than 10 minutes

$\square$ Pain prevents me from sitting at all

\section{Section 6 - Standing}

$\square \quad$ I can stand as long as I want without extra pain

$\square$ I can stand as long as I want but it gives me extra pain

$\square \quad$ Pain prevents me from standing for more than 1 hour

$\square \quad$ Pain prevents me from standing for more than 30 minutes

$\square \quad$ Pain prevents me from standing for more than 10 minutes

Pain prevents me from standing at all

\section{Section 7 - Sleeping}

My sleep is never disturbed by pain

My sleep is occasionally disturbed by pain

Because of pain I have less than 6 hours sleep

Because of pain I have less than 4 hours sleep

Because of pain I have less than 2 hours sleep

Pain prevents me from sleeping at all

\section{Section 8 - Sex life (if applicable)}

My sex life is normal and causes no extra pain

My sex life is normal but causes some extra pain

$\square \quad$ My sex life is nearly normal but is very painful My sex life is severely restricted by pain

$\square$ My sex life is nearly absent because of pain

$\square \quad$ Pain prevents any sex life at all

\section{Section 9 - Social life}

$\square$ My social life is normal and gives me no extra pain

$\square \quad$ My social life is normal but increases the degree of pain

$\square \quad$ Pain has no significant effect on my social life apart from limiting my more energetic interests eg, sport

$\square \quad$ Pain has restricted my social life and I do not go out as often

Pain has restricted my social life to my home

$\square$ I have no social life because of pain

Section 10 - Travelling

I can travel anywhere without pain

I can travel anywhere but it gives me extra pain

Pain is bad but I manage journeys over two hours

$\square \quad$ Pain restricts me to journeys of less than one hour

Pain restricts me to short necessary journeys under 30 minutes

$\square \quad$ Pain prevents me from travelling except to receive treatment 